\title{
Gratification disorder in a toddler: perils of excess screen time
}

\author{
Rajesh Rai, Neelu Elon, Prithi Inamdar, Swetha Chowdary*, Bhavya S. Kaniti
}

Department of Pediatrics, Dr. DY Patil Hospital, Nerul, Navi Mumbai, Maharashtra, India

Received: 10 January 2022

Accepted: 01 February 2022

\section{*Correspondence:}

Dr. Swetha Chowdary,

E-mail: swethachowdary.narra@gmail.com

Copyright: ( $)$ the author(s), publisher and licensee Medip Academy. This is an open-access article distributed under the terms of the Creative Commons Attribution Non-Commercial License, which permits unrestricted non-commercial use, distribution, and reproduction in any medium, provided the original work is properly cited.

\begin{abstract}
Infantile gratification (masturbation) is a self-stimulatory psychological behavior that is often misdiagnosed as epilepsy. It is more common in girls, occurs at 2-3 years of age and is often associated with perspiration, irregular breathing and grunting, but no loss of consciousness. Occasionally this is associated with child abuse or other psychopathology.
\end{abstract}

Keywords: Infantile gratification, Psychopathology, Toddler

\section{INTRODUCTION}

Infantile gratification disorder is a self-stimulatory behaviour that is often misdiagnosed and sparingly reported in literature posing challenges to clinicians. Selfgratification has been confused with neurological disorders, movement disorders, epilepsy and in certain situations even abdominal colic and spasms. ${ }^{1}$ This results in a battery of investigations from varied blood tests, imaging and electroencephalography. There have also been instances of anti-epileptic medications being started in children with the condition. ${ }^{2}$ Self-gratification is now considered a normal behavior in pediatric age group and generally considered to be benign. Gratification disorder have been reported in $90-94 \%$ of males and 50 to $60 \%$ of females. ${ }^{3}$ In India, self-gratification is still viewed as a social stigma in society. This brings in an additional challenge in counselling the parents and sensitizing them to the condition. Here we report a case of a 3-year old girl who presented with gratification disorder mimicking movement disorder.

\section{CASE REPORT}

A 3-year old girl was brought to the outpatient clinic of the department of paediatrics at our tertiary care teaching hospital with complaints of episodic abnormal movements and posturing of both the lower limbs. Movements were described as periodic rocking and twisting of the lower limbs associated with hyperventilation, and sweating. She was observed to be fully conscious and also responded to calls during each episode which lasted for 10-15 minutes. Similar episodes were repeated multiple times in a day. The movements were discontinued when the child was presented with a video of choice from a web streaming service. However, once the web streaming was withdrawn, the child reverted to the aforementioned movements. Additionally, movements were not present during sleep. It was confirmed by the mother that there was no history of sexual abuse. She was delivered full term with no significant neonatal history and no history of developmental delay. She was initially misdiagnosed with epilepsy and had been started on phenobarbitone before visiting our outpatient department (OPD). She is born into a non-consanguineous marriage. She is the older of two children. The father is a farmer, while the mother is a house wife. There was no significant family history. Metabolic workup was normal. An electroencephalography was done to rule out the possibility of epilepsy which was reported normal. A home video recording and a video recorded in our hospital showed behaviour consistent with gratification. The diagnosis of childhood gratification disorder was confirmed. The parents were informed and explained about the benign nature of the behaviour. They were advised to engage the child with interactive play during episodes and also gradually discontinue her 
obsession to web streaming services. She is currently being followed-up at the paediatric OPD.

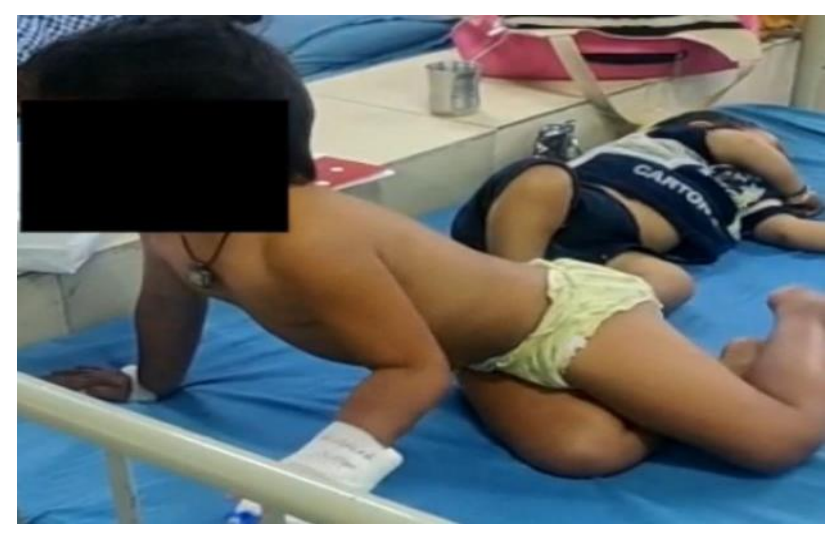

Figure 1: Gratification disorder.

\section{DISCUSSION}

Self-gratification is considered a variant of normal sexual behaviour. In contrast to adolescents and adults, the absence of genital manipulation makes the diagnosis of masturbation in children difficult. ${ }^{3}$ The term gratification or benign idiopathic infantile dyskinesia is preferred to masturbation while referring to the condition, as there is social stigma while mentioning the former. Selfgratification is likely initiated once the child is left alone without activity, discovers the pleasant and comforting sensation, which is likely to subside once the child becomes engaged in other objects or activities in the environment. ${ }^{4}$

There as a number of physiologic changes which occurs in stages. The stages are the initial excitement phase followed by the plateau phase and finally the resolution phase. In the excitement phase, a sharp increase in heart rate, respiratory rate, and blood pressure is accompanied by muscular contraction. There is an involuntary posturing which occurs in this phase due to the simultaneous contraction of the lower back, buttocks and pelvic muscles. ${ }^{5}$ The plateau phase is characterised by rhythmic contractions and occasionally the body may stiffen. Finally in the resolution phase, the body relaxes with release of blood from the engorged muscles, with profuse sweating, grunting and hyperventilation. The changes are less well recognised in infants and toddlers. ${ }^{6}$

A clinician must be aware of the condition as its unique clinical presentation is a challenge. The varied presentation along with the absence of classical signs such as genital stimulation and presence of signs such as abnormal posturing may result in a wrong diagnosis. This would further lead to unwarranted investigations and administration of unwanted medications such as antiepileptics. ${ }^{2}$ A review of 31 cases had demonstrated seizure disorder to be the most common misdiagnosis. ${ }^{7}$ However there have been other reports suggesting movement disorders to be the most common initial diagnosis of gratification disorder. ${ }^{8}$ The case that we have described here was also diagnosed with seizure disorder and was started on phenobarbitone before presenting to us. Once the diagnosis of masturbatory behaviour is made, a history of sexual abuse and perineal irritation should be ruled out. ${ }^{3,9}$

Digital devices have become an integral part of households and their use can begin at very young ages. ${ }^{10}$ Although their effects are positive, their excessive use or misuse among a minority may become problematic and have a negative impact on educational, psychological, social, and physical well-being. A disturbing trend that has been described is the inverse relationship between age and the addiction of these devices. ${ }^{11}$ There is growing evidence demonstrating the role of the internet, social media and web streaming in gratification seeking behaviour among adolescents. ${ }^{12}$ Internet is seen to cause acute and sustained alterations in areas of cognition by stimulating the brain, which have been documented by neuroimaging. ${ }^{13}$ This is important in context to our case as there was a clear relationship with use of these services and onset of the gratification behaviour, however there are no evidence linking gratification disorder with use of internet among toddlers. We would like to draw attention to the fact that the child withdrew from the gratification activity when a video from a web streaming service was introduced. Various organisations such as American academy of pediatrics have introduction of guidelines for media use in children. ${ }^{14,15}$

Yang et al have summarised the clinical features which are suggestive of gratification disorders as follows. ${ }^{16}$

Table 1: Clinical features which are suggestive of gratification disorders by Yang et al.

\begin{tabular}{|ll|}
\hline Sl. no. & Clinical features \\
\hline $\mathbf{1}$ & $\begin{array}{l}\text { Onset after the age of } 3 \text { months and before } 3 \\
\text { years }\end{array}$ \\
\hline $\mathbf{2}$ & Stereotyped episodes of variable duration \\
\hline $\mathbf{3}$ & Vocalizations with quiet grunting \\
\hline $\mathbf{4}$ & Facial flushing with diaphoresis \\
\hline $\mathbf{5}$ & $\begin{array}{l}\text { Pressure on the perineum with characteristic } \\
\text { posturing of the lower extremities }\end{array}$ \\
\hline $\mathbf{6}$ & No alteration of consciousness \\
\hline $\mathbf{7}$ & Cessation with distraction \\
\hline $\mathbf{8}$ & Normal examination \\
\hline $\mathbf{9}$ & Normal laboratory studies \\
\hline
\end{tabular}

A home video recording of the episode will help in confirming the diagnosis as the history provided by the parents may be misleading. Once the diagnosis is made, treatment involves counselling and educating the parents that it is a normal behaviour and they will outgrow it. Diverting the child's attention to other activities has been found to be effective in controlling self-gratification. The excessive interest in web streaming services in children should be controlled by encouraging the child to engage in 
different forms of non-digital and other recreational activities aimed at physical, mental and emotional development. Aggressive response to the self-gratifying activity should be avoided as it is found to have a negative impact on the child. ${ }^{17}$

\section{CONCLUSION}

We have noticed a significant association of withdrawal of media exposure (web streaming) with gratification behaviour in this patient. We postulate that prolonged media exposure leads to continuous stimulation of the brain and that withdrawal from it leads to dissatisfaction. This results in gratification behaviour to compensate for the loss of the said stimulatory brain activity. Hence we suggest that reducing the screen time and indulge in other activities would help to overcome this disorder.

Funding: No funding sources Conflict of interest: None declared

Ethical approval: Not required

\section{REFERENCES}

1. Jan M, Albanji M, Fallatah B. Long-term Outcome of Infantile Gratification Phenomena. The Canadian journal of neurological sciences. Le journal canadien des sciences neurologiques. 2013;40:416-9.

2. Bradley SJ. Childhood female masturbation. Can Med Assoc J. 1985;132:1165-6.

3. Leung AK, Robson WLM. Childhood masturbation. Clin Pediatr (Phila). 1993;32:238-41.

4. Shuper A, Mimouni M. Problems of differentiation between epilepsy and non-epileptic paroxysmal events in the first year of life. Arch Dis Child. 1995;73:342-4.

5. Masters WH, Johnson VE. Human Sexual Response. Boston, MA: Little, Brown and Company. 1966.

6. Mink JW, Neil JJ. Masturbation mimicking paroxysmal dystonia or dyskinesia in a young girl. Mov Disord. 1995;10:518-20.

7. Nechay A, Ross LM, Stephenson JB, O’Regan M. Gratification disorder ("infantile masturbation"): A review. Arch Dis Child. 2004;89:225-6.

8. Fleisher DR, Morrison A. Masturbation mimicking abdominal pain or seizures in young girls. J Pediatr. 1990;116:810-4.
9. Sauzier M. Sexual abuse of children and adolescents. Audio Dig Psychiatry. 1984;13(17).

10. Samaha M, Hawi NS. Associations between screen media parenting practices and children's screen time in Lebanon. Telematics and Informatics. 2017;34:351-8.

11. Andreassen C, Billieux J, Griffiths MD. The relationship between addictive use of social media and video games and symptoms of psychiatric disorders: a large-scale cross-sectional study. Psychology of Addictive Behaviors. 2016;30:252.

12. Leung L. Predicting Internet risks: a longitudinal panel study of gratifications-sought, Internet addiction symptoms, and social media use among children and adolescents. Health Psychology \& Behavioural Medicine. 2014;2(1):424-39.

13. Firth J, Torous J, Stubbs B, Firth JA, Steiner GZ, Smith L, Alvarez-Jimenez M, Gleeson J, Vancampfort D, Armitage CJ, Sarris J. The "online brain": how the Internet may be changing our cognition. World Psychiatry. 2019;18(2):119-29.

14. Council on Communications And Media. Media Use in School-Aged Children and Adolescents. Pediatrics. 2016;138(5):e20162592.

15. Canadian Paediatric Society, Digital Health Task Force, Ottawa, Ontario. Digital media: Promoting healthy screen use in school-aged children and adolescents. Paediatr Child Health. 2019;24(6):40217.

16. Yang ML, Fullwood E, Goldstein J, Mink JW. Masturbation in infancy and early childhood presenting as a movement disorder: 12 Cases and a review of the literature. Pediatrics. 2005;116;142732.

17. Ibrahim A, Raymond B. Gratification disorder mimicking childhood epilepsy in an 18-month-old Nigerian girl: A case report and review of the literature. Indian J Psychol Med. 2013;35:417-9.

Cite this article as: Rai R, Elon N, Inamdar P, Chowdary S, Kaniti BS. Gratification disorder in a toddler: perils of excess screen time. Int J Contemp Pediatr 2022;9:289-91. 